\title{
Las aguas como lugar de origen de la creación de José Ángel Valente
}

\author{
Water as the source of creation in José Ángel Valente's work
}

\author{
Guillermo Aguirre MartíneZ \\ Universidad Complutense de Madrid. Madrid, España \\ guillermo-aguirre@hotmail.com
}

\section{RESUMEN}

El agua, unida simbólicamente a lo matriarcal, va a presentarse como elemento desde donde surgirá la creación lírica de José Ángel Valente. Como ámbito propicio para toda disolución, el poeta buscará con su inmersión en ella desconfigurar toda una serie de dogmas y ortodoxias nocivas de cara al hecho estético. El descenso a un mundo abismal, arquetípico, permitirá al creador recoger de su fondo una serie de imágenes que, en su completo desarrollo, permitirá la creación de un cosmos simbólico llamado a reunir un plano sensible y material con aquel otro abstracto y espiritual. El descenso del poeta a unos niveles primordiales de la creación se podrá comprender, a su vez, como necesario ritual de disolución del orden construido con vistas a renovar la comprensión del cosmos poético que se va a ir gestando. La observación y el análisis de estos hechos será cuanto llevemos a cabo a lo largo de las siguientes páginas.

Palabras clave: Poesía española, arquetipo matriarcal, imaginario, símbolo.

\section{ABSTRACT}

As a matriarchal symbol, water is the element from which José Ángel Valente's poetry emerges. But water is not only a matriarchal symbol but also an element of destruction, which is able to break down dogmas and orthodoxies -all of which are considered dangerous to the aesthetic purpose. So, from the depths of this symbolical water, José Ángel Valente is going to search his own poetic voice and to create his own universe of symbols. All these symbols will enable him to join material aspects with 
those spirituals aspects of his poetry. This descend into matter will be undestood like a process of disolution in order to rethink the poet's symbolic universe. A comparison and analysis of these aspects will be developed of this paper.

Keywords: Spanish poetry, matriarchal archetype, imaginary, symbol.

Recibido: 05.04.2012. Aceptado: 05.09.2012.

\section{DIFERENTES ESTADIOS CREATIVOS}

Colía mencionar José Ángel Valente (1929-2000) que su origen, el mundo $\checkmark$ que trataba de recuperar mediante su poesía, se desarrolló en un entorno de cuidados matriarcales, en un ámbito donde el calor y el cariño animaban a crecer. Esta cultura matriarcal la consideraba propia no sólo de todo el espacio gallego, sino como definitoria del mismo acto de creación. El predominio de un orden materno venía a identificarse, a partir de presupuestos psicológicos-antropológicos en boga, con un mundo sublunar, elemental y, por consiguiente, inclinado al establecimiento de una serie de equiparaciones proclives a tratar la creación como un proceso surgido de las aguas, del barro, de lo generativo; un proceso que se elevaba hacia la superficie o trataba de hacerlo para, de este modo, lograr su completo desarrollo ya en un plano puramente espiritual. El propósito del artista, desde esta perspectiva, sería el de reunir aquel aspecto intuitivo soterrado por nuestra naturaleza fuertemente racional, con este mismo orden racional comprendido no ya como elemento opresor sino como aquel otro capaz de encaminar nuestro universo bullente y sensible hacia un orden diurno; logrando, con dicha reunión, el abrazo entre sustancia y forma.

Desde estos parámetros, el propio autor comentará que

en la creación, el andrógino es un símbolo absolutamente clave. Cada escritor, hombre o mujer, tiene una androginia fundamental. Desde el punto de vista masculino, el hombre tiene que dar una gran libertad a su elemento femenino para que salgan en él los elementos de sensibilidad, de imaginación, que son propios de éste (Valente y Fernández, 2000: 141).

Esta androginia, lograda a través del descenso a un mundo de imágenes y su posterior representación mediante la imagen simbólica -núcleo de reunión entre lo sustancial y lo formal, lo figurativo y lo abstracto-, permitirá precisamente la consecución de cuanto el símbolo mismo ya posee dada su 
naturaleza binaria, esto es, la reunión de aquellos dos planos ya mencionados del ser, en principio aislados. Por todo ello, podemos decir que mediante el acto de creación se asiste a un proceso de anagnórisis, de recuperación de una unidad perdida al compás del desarrollo paulatino de nuestra naturaleza eminentemente técnica, en detrimento de nuestra capacidad intuitiva.

El poeta, mediante el verbo, se convertirá en elemento mediador entre un mundo material y otro espiritual, entre lo humano y lo divino, capaz de acumular la densidad simbólica suficiente para así llegar a intuiciones inmediatas, trazando un recorrido que le llevará a entregarse, antes que a la búsqueda de Dios -apreciable en la etapa última de su trayectoria-, a un descenso a los órdenes subterráneos donde el imaginario humano sitúa a la Gran Madre, a la naturaleza creadora y destructora a un mismo tiempo, lugar de concentración de aquellos elementos que el hombre -con su orden de categorías y jerarquías- separa, tal y como nos narrará en su ensayo sobre el tema Erich Neumann:

Una de las características esenciales del arquetipo originario consiste en cambiar de manera simultánea atributos positivos y negativos. Esta coincidencia oppositorum del arquetipo originario, su constituir una entidad ambigua y equívoca que contiene los opuestos, es característica de la situación original de un inconsciente en el que la conciencia no ha procedido todavía a la separación de los contrarios (2009: 27).

El creador, con su descenso a los limos, se presentará como mediador, como figura salvadora dentro de un orden mítico e indeterminado.

Dejando de lado un posterior estadio observable en la trayectoria poética de José Ángel Valente comprendido a modo de orden intermedio en el que los contrarios comienzan a fusionarse, a entregarse los unos a los otros en un erótico acto previo a la individualización de cada elemento; dejando aun de lado una última búsqueda estética realizada en torno a una esfera trascendental donde la materia no tiene ya cabida y el poeta se ve obligado a callar, detendremos nuestra mirada en los elementos madre de su creación, en aquel terreno de confusión habitado por las aguas, el barro, la tierra y, en fin, todo lo relativo a un cosmos germinal, con el propósito de comprender el modo y las encarnaciones con que las diferentes imágenes surgen de estas fuentes y acaban por ampliar el espectro simbólico propio de la poesía del autor gallego.

Hasta esos estratos no aptos para la pervivencia de lo consciente sino sólo para el mero fluir de imágenes, para lo irracional, descenderá el creador tal y 
como él mismo canta en los siguientes versos de Interior con figuras

Aquí desnudo estoy,

ante el espasmo poderoso del dios.

Aquí está el límite.

Ya nunca,

oscuros por la sombra bajo la noche sola, podríamos volver.

Pero no cedas, baja

al antro donde

se envuelve en sombras la verdad.

$\mathrm{Y}$ bebe, de bruces, como animal herido, bebe su tiniebla,

al fin (2006: 362-363).

En estos espacios los elementos se van a presentar desprovistos de forma cierta, guardando en torno a ellos una serie de adherencias, de sedimentos propios de su estado larvario; los órdenes se confunden en el vasto caudal de la memoria poética para así llevarlos a la forma, a la claridad: "Porque morir fue al cabo / el solo modo de vencer la muerte / y no era inútil / la vocación, el fuego o el destino nuestro" (Valente, 2006: 349). Encontramos en estas hondas profundidades el lugar donde Valente realizará aquella tarea de su búsqueda poética encaminada a despojarse de todas aquellas categorías sobreimpuestas, momento en que estará ya preparado para dejar atrás un orden elemental y paulatinamente abrirse paso hacia unas cimas donde luchará por fusionarse con una mística nada: "Yo estoy llegando a ti y aún no toco tu borde, en el que ya se abrasa la memoria” (2006: 411), una memoria comprendida como última posesión individual que ahora deberá ser igualmente vaciada, toda vez que

como la oscuridad y el silencio, el vacío es una negación que aleja la conciencia del aquí y del ahora, y de esta suerte hace presente y actual eso que hemos llamado 'lo absolutamente heterogéneo' (Otto, 2009: 98).

\section{EN LOS ESTRATOS ELEMENTALES DE LA CREACIÓN}

Nos situamos de lleno en un espacio prerracional donde el poeta va a encontrar, fruto de su vertiginoso descenso al mundo de los arquetipos, un universo de imágenes puras, cambiantes y sin significación alguna; nos presentamos en unos abismos donde esas mismas imágenes guardan aún intacta 
su capacidad de designar en función de su plurivalencia total, de su no determinación por el espectro de categorías humanas. En estos estadios, puede decirse, la palabra, la voz, permanecerá apegada a su exclusiva sustancialidad, a sus ritmos elementales y su mera sonoridad sin más, conformando un hermoso y caótico lienzo donde todo se abraza porque nada aún ha sido individualizado. Comenta al respecto Juan Eduardo Cirlot que

toda creación nace más allá de los límites del lenguaje [...]. Es poesía profunda y verdadera la que nos devuelve a ese inexpresable silencio que precede a la dicción, o a la simple conexión psicológica de todo el concierto inefable de armonías lejanas, cuya disonancia excita la sensibilidad y abre las puertas del éxtasis (2005: 673).

Este hondo sustrato disolutivo en donde todo se prepara para comenzar a tomar forma, se corresponderá con un simbólico descenso del autor a los infiernos, una sintomática muerte ya presentada con todos sus matices por el autor en sus Poemas a Lázaro, tercero de sus poemarios: "Descendamos después / y entre la multitud de los que llegan, / con paso lento / y el corazón entero en la firmeza, / ingresemos despacio en la enorme salida" (2006: 160). Fenómenos de disolución dominarán todavía sobre cristalizaciones y formaciones, mientras que el poeta, incapaz de aprehender durante más de un instante imagen alguna pues nada sedimenta, conformará un crisol de plásticas formas que irá alzando a la luz para al momento asentarlas de nuevo como informe materia. Se llega así a un ansiado grado cero, núcleo de indeterminación absoluta, lienzo impoluto donde nada arraiga pues lo sustancial, la materia trabajada por el poeta, se corresponde aún plenamente con la puramente cuantitativo, aquello que carece de unidad pues pertenece al orden de lo no engendrado, marea incesante de formas devueltas, una y otra vez, a los cauces del fondo creador: "Sería al fin como volver a hundirse / branquial entre tus aguas poderosas, / indescifrable madre?" (Valente, 2006: 289), se pregunta el sujeto lírico ante la contemplación de un fondo tan intensamente presente a lo largo del poemario El inocente. La muerte simbólica del poeta, como vamos viendo, se corresponderá con la disolución de un mundo de estructuras consolidadas y con la apertura a un fluido de imágenes comprendidas a modo de liberación de aquel estrato materno de tanta presencia en nuestro poeta.

En relación a este aspecto, en los versos de "Territorio", pieza perteneciente a Interior con figuras, leeremos muy denotativamente: 
Ahora entramos en la penetración, en el reverso incisivo de cuanto infinitamente se divide. Entramos en la sombra partida, en la cópula de la noche con el dios que revienta en sus entrañas, en la partición indolora de la célula, en el revés de la pupila, en la extremidad de la materia o en su solo comienzo (Valente, 2006: 339).

Esta entrada en materia a la que acabamos de asistir será comprendida como una involución de la conciencia, un vaciamiento previo de toda abstracción necesaria para proceder, a partir de ahí, a un inocente descubrir el mundo no ya desde los hechos, desde las formaciones, sino desde su desarrollo interno. La descripción fuertemente sexual que Valente realiza de este proceso nos remite a un modelo de gnosis bien conocido por Carl Gustav Jung (2002) y su escuela, mediante el cual, el mediador -poeta o héroe que ha descendido a los infiernos- debe enfrentarse a un alter ego comprendido como elemento opresor -simbólico dragón- de su propia naturaleza con el fin de rescatar de este pozo de la conciencia, de este estrato dominado por fuerzas disolutivas entendidas como elementos maternos desde la psicología arquetípica, todas aquellas potencias aún sin sublimar con el propósito de realzarlas hacia niveles elevados de manifestación, de lucidez, permitiendo a través de esta dialéctica ascensional el surgimiento de la famosa autoconciencia postulada por Hegel como visión preclara de nuestro propio tesoro espiritual.

Este derramamiento de sangre por el que todo nuestro juicio racional queda deshecho, permitirá al poeta alcanzar el vaciamiento deseado, presentarse allí donde "en el centro inmóvil bebe / la luz desnuda todo lo visible" (Valente, 2006: 365), alcanzando el fondo blanco tan característico de su poesía a modo de coronación última de todo el proceso disolutivo. El sujeto habrá alcanzado, con este último acto de disolución, el "punto cero, el punto de indeterminación infinita, de la infinita libertad" (Valente, 1980: 9), desde donde podrá levantar un lenguaje personal, un cosmos simbólico nuevo y creado no ya desde el lenguaje heredado sino desde aquel otro liberado, "El silencio se quiebra / en trino por tres veces / y la materia de la música / ya no es sonido sino transparencia" (Valente, 2006: 363). 
Este desenvolvimiento poético, trasladado a un terreno mítico-psicológico rico en analogías y significaciones anímicas, va a ser comentado con inusual claridad por Neumann, quien expondrá que "la relación dialéctica de la conciencia con lo inconsciente adopta la figura simbólico-mitológica de un enfrentamiento entre la madre femenina y el retoño masculino" (2009: 154), fenómeno consecuente a una íntima "relación entre el amante filial y la Gran Madre" -relación puesta de relieve por el mismo Valente al inicio de estas páginas-, y a "la fase del combate heroico entre el héroe masculino y la Gran Madre" (Neumann, 2009: 154), momento de desencuentro entre ambos una vez que el sujeto lírico desciende al reino de la voluntad y se prepara para volver con la sabiduría conquistada a unos más tranquilos ámbitos de conciencia lumínica y claridad:

No detenerse.

Y cuando ya parezca que has naufragado para siempre en los ciegos meandros

de la luz, beber aún en la desposesión oscura,

en donde sólo nace el sol radiante de la noche (Valente, 2006: 372).

Como vamos viendo, estos dos últimos estadios mencionados propios del proceso de conocimiento estético -la relación erótica entre el creador y la Gran Madre, y su combate final con ella-, podrán ser observados de modo continuo mediante su representación a lo largo de un periodo medio de la obra de Valente. Este hecho se corresponderá fundamentalmente con el encuentro gozoso del sujeto lírico con sus orígenes, con todo aquello que le remonta a su infancia, y la posterior huida del seno de este origen en pos de un desarrollo imposible de completar desde estos terrenos pantanosos propicios para acumular savia pero no para germinar con fuerza hacia un orden espiritual.

\section{LA PALABRA COMO ANIMAL SUBTERRÁNEO}

La palabra poética, definida por el autor como lugar de la absoluta interioridad, como espacio desde el que resulta posible el retraimiento hacia lo más descondicionado de uno mismo, se presentará como único elemento sólido en este pasillo de entrada desde el mundo de la voluntad al de la representación, 
Al final sólo queda

la voz, la voz, la poderosa voz

de la llamada:

-Lázaro,

ven fuera.

Animal de la noche,

sierpe, ven, da forma

a todo lo borrado (Valente, 2006: 340).

De la voz sólo nos llegará un son, un decir carente de significado, un algo musical en tanto que, siguiendo a Schopenhauer, lo melódico, dada su imposibilidad de representarse sensiblemente, se comprenderá como la expresión más veraz de la voluntad pura:

para que $[\ldots]$ aquí y allí la música nos lleve

al centro, al fuego, al aire,

al agua antenatal que envuelve

la forma indescifrable

de lo que nunca nadie aún ha hecho

nacer en la mañana del mundo (Valente, 2006: 364).

Este centro, este encuentro del sujeto lírico con un orden observado como espacio materno, como lugar donde muere todo rastro de individualidad, permitirá una nueva configuración espiritual al tiempo que mantendrá la amenaza de enterrar definitivamente la luz del poeta -su verbo- en unos dominios caóticos e irracionales, en el seno de una naturaleza disolutiva donde no queda ya estructura alguna sobre la que apoyarse mediante el mero razonamiento; fenómeno observable a través de las estrofas de 'Voz desde el fondo', también de Interior con figuras:

Yo hablaba debajo de tu cuerpo,

cubierto por tu cuerpo, cubierto por la altura de tu cuerpo desnudo.

Las palabras formaban más allá de tus hombros,

al tocar el nivel opaco de la vida, transparentes burbujas.

Nada significaba

su pura luz, transparencia o señal

del fondo sólo (Valente, 2006: 348). 
En este punto disolutivo, en este encuentro con la naturaleza caótica, el creador quedará sometido a fuerzas disgregadoras pero, a su vez o por ello mismo, posibilitado de iniciar un ascenso o retorno hacia un orden comprendido ya no desde su mera exterioridad sino desde su forma viva, comprendido a través de su espíritu dinámico.

Desde estos órdenes inferiores, desde esta voluntad pura, el poeta no podrá descifrar sino un fondo blanco vacío de significación y de imposible designación, permitiendo así el surgir limpio del verbo, sin sedimentos o "perfiles desmaquillados, / huellas rotas, / irredentas partidas bautismales" (Valente, 2006: 343), del mismo modo al comentado por Michel de Certeau cuando indica que "el propio Verbo debe nacer en el vacío que lo atiende" (2006: 15). Las formas, por ello mismo, más allá de un proceso de categorización propiamente conceptual, quedarán suspendidas sobre una nada, sobre un fondo amenazador en ocasiones, consolatorio en otras, del que surge, precisamente, la voz lírica. De este modo lo podemos apreciar en los versos de "Para una imagen rota", siguiendo con el último poemario: "Mira el vacío en su plenario rostro. / Míralo sin llanto, / como quien ha sabido conjurar la muerte" (Valente, 2006: 344). Desde este polo extremo a la toma de conciencia, va a quedar el poeta perplejo ante la absoluta indeterminación, ante la naturaleza sustancial propia de la materia. No habitará aquí una divinidad lumínica sino una fuerza permanentemente transformadora, una materia en continuo dinamismo sin rastro alguno, sin embargo, de aquella divinidad buscada con ahínco por el poeta especialmente en un periodo siguiente de su obra, momento en el que se acercará en lo posible a una nada de honda raíz mística, ardua cuando no imposible de descifrar.

Entretanto el sujeto se irá conformando con un simple palpar, un aprehender las formas que ante él se van presentando dentro de un espacio de espesa materialidad, "Entró en el tacto, subió hasta el paladar, / estableció su reino / en la saliva última / donde los limos del amor reposan" (Valente, 2006: 347). Ni rastro, como vemos, del elemento divino más allá de unos ecos remotos comprendidos a modo de incognoscibles pulsiones, de ritmos primarios que, más adelante, una vez filtrados por el tamiz de la conciencia, darán paso a la configuración de la palabra poética: "Conviene percutir. I Conviene que el tambor nos posea. / Porque en el tambor está, nos dijeron, / el ruido sin fin del fundamento". Acto seguido, el poeta acabará con dos versos de hondo significado en lo relativo a la proyección simbólica del cosmos a erigir: "Con la piel del pez hicieron un tambor, / pero el pez era un dios" (Valente, 2006: 349). En este punto hemos de detenernos toda vez que la asimilación del verbo con el pez nos remontará a unos fundamentos 
primeros del lenguaje al tiempo que adelanta, mediante explícitas asociaciones, la triple naturaleza del pez-sierpe-ave como resultado del poder propio de la palabra liberada, de aquella naturaleza simbólica que permitirá que el poeta se alce de manera alada hacia estratos propiamente conceptuales. Cuanto logrará el autor como fruto de este proceso, será aunar en la medida de lo posible un universo en el que el aspecto más primario y elemental de la voz, su rítmico son, se conjugará con aquel otro más espiritualizado y elevado, posibilitando con ello la comprensión de dicha voz como "lugar de las revelaciones [...], espacio en el que la verdad se manifiesta y se enuncia a la vez" (Foucault, 2010: 44).

Como proyección natural de estas transformaciones, la presentación de polos en principio opuestos a través de la imagen reflejará la reunión satisfactoria entre un orden matriarcal y otro próximo a lo patriarcal, toda vez que "lo que asciende une las fuerzas de lo inferior con las de lo superior y revela toda su potencia cuando retorna a la tierra" (Jung, 2002: 222). De este modo, por ejemplo, la conjunción de lo alado con lo subterráneo engendrará lo terrestre: "Dragón / (acoplado a la trucha / engendra el elefante)" (Valente, 2006: 342), según leemos en los versos de "Poética", definitorios, como el título refleja, de la comprensión del fenómeno de la creación tal y como la presenta José Ángel Valente. Este desarrollo completo y tremendamente enérgico se podrá apreciar asimismo bajo formas de reunión tradicionales como el árbol o el mismo ser humano, según observaremos en el poema "Elegía, el árbol", cuyo inicio bastará para observar nuevamente el doble orden permanentemente representado en este periodo nuclear de la obra del autor:

El árbol pertenecía por la copa a lo sutil, al aire y a los pájaros. Por el tronco, a la germinación y a todo lo que une lo celeste con los dioses del fondo. Por la raíz oscura, a las secretas aguas (2006: 359).

Una vez más, quedará clara la necesidad del descenso a unos estratos elementales como requisito para la renovación del lenguaje y, consecuentemente, del imaginario simbólico del poeta. A partir de ahí, a partir de esta reorganización, el sujeto lírico podrá acercarse en la medida de lo posible hacia un régimen diurno, solar, no comprendido ya como lugar del dogma sino como unión de la ansiada fusión de contrarios, mencionada por el propio autor bajo la explícita imagen de la "hembra solar" (Valente, 2006: 557), conjunción lograda entre los polos enfrentados a modo de luz y oscuridad. Cabe indicar, en cualquier caso -y de ahí la no validez absoluta de cuanto 
se habrá logrado- que la unión de ambos órdenes va a acaecer dentro del universo sensible del poeta -en un plano estético, por lo tanto-, quedando al margen un espacio abismal o suprapoético que en momento alguno se podrá reunir con un orden sensible material dada la tremenda oposición con que en la obra de Valente van a convivir ambos espacios propios de su imaginario.

\section{LA ATRACCIÓN DEL CENTRO}

Una vez alcanzado un espacio germinal, un centro libre de ortodoxias, la poesía de Valente, tras haber realizado un enorme derroche de fuerzas representadas a modo de imágenes absorbidas por ese mismo centro, por una nada de la que habrá de surgir la creación con renovadas fuerzas, no tendrá otra salida que comenzar a reconstruir un mundo de naturaleza incierta en tanto que en la desarticulación completa del sentido no ha hecho su aparición la ansiada epifanía: "Palabra / hecha de nada. / Rama / en el aire vacío. / Ala / sin pájaro” (2006: 379). El sujeto lírico se entregará en estas simas a un "continuo girar en torno al centro ausente, un inquieto merodear en el vacío" (García, 2010: 293), antes de emprender el ascenso en pos de su encuentro con lo divino. Este último encuentro, como hemos mencionado, no podrá realizarse en tanto que el poeta buscará a través de un plano estético aquello que se ha de consolidar primeramente sobre un espacio espiritual actitud comúnmente adoptada por buena parte del arte contemporáneo. De esta manera, aquel centro comprendido como fondo absoluto de un orden nocturno se presentará como paralelo a aquel otro alcanzado a modo de vértice último del orden diurno, en tanto que el poeta, guiado por un escepticismo nacido exclusivamente de su interior, no encontrará al Dios buscado ni como sustentador de un orden material ni como custodio de un orden espiritual, quedando recluido en su propio universo poético precisamente como consecuencia del deseo de acercarse a un espacio trascendental desde una esfera exclusivamente sensible: "Tú dices, vienes, / estás, no hay nadie aún en la inundada / extensión de la noche" (Valente, 2006: 483). Llegado el caso, el vacío en torno al cual merodea el creador, se presentará como proyección lógica de su cosmovisión materialista y no ya como lugar de epifanía, quedando resignado el poeta al desarrollo de un esfuerzo infructuoso por conseguir a través de la imagen cuanto precede -ya desde la afirmación, ya desde la negación- a la experiencia estética.

Esta duda metafísica que domina y sustenta el pensamiento de José Án- 
gel Valente puede ser rastreada en cualquier época de su trayectoria; así, dentro del periodo que venimos estudiando, en "Invención sobre un perpetuum mobile”, elocuente al respecto, podemos leer que

El prestidigitador ocultó el mundo en su pañuelo y a la hora de hallarlo olvidó el truco.

Después él mismo desapareció dentro de su chistera indescifrable mientras lloraban los espectadores, a su vez no visibles, pues también eran parte del mundo reducido en un azar de nadas a la nada [...] queda la arena y el foco circular y, en su centro, el niño del dadá, hop, hop, sobre la música abolida nunca (2006: 366).

Ni rastro de dioses; el sujeto permanecerá encerrado en un mundo de formas carentes de propósito alguno más allá del de su constante renovación. Frente a este paisaje, pese a su deseo de privilegiar un mundo material sin rasgos de individualización, el sujeto poético, confundido en el seno de su propio orden creativo, tratará inmediatamente de alzarse hacia el demiurgo a través de la depuración absoluta del universo erigido. Como es de prever, el poeta topará con un nuevo vacío imposible de descifrar en tanto que más allá del silencio no quedará el Dios sino, tal y como ya experimentó en un orden material, una permanente duda:

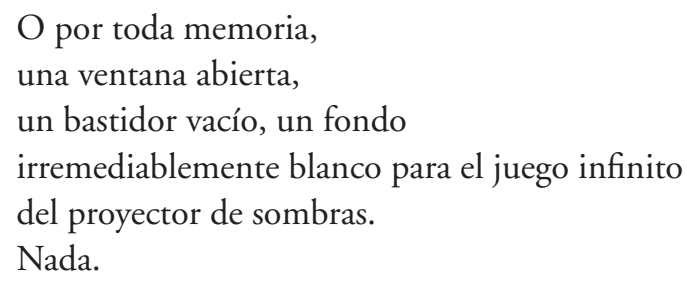

De ser posible, nada (Valente, 2006: 343).

Frente al apogeo vivido en un orden sensible donde asistimos a la conciliación entre orden intuitivo y racional, lunar y solar, cuanto observamos en estos márgenes elevados será la colisión tremenda entre lo sensible y lo espiritual toda vez que su descreencia anímica nacerá de la imposibilidad 
de alcanzar dicho absoluto prescindiendo de la materia, impidiendo así el desarrollo metafísico de su realización estética.

Volviendo a nuestro universo germinal, podremos observar cómo el universo que nos presenta Valente en estos espacios abismales resulta simbolizado por una madre devoradora y devorada a un mismo tiempo, un continuo removerse de unas formas que, incesantes, se transforman en nuevos espectros; un continuo virar y virar que, en ocasiones, escasas, asiste por breves instantes al "súbito encuentro / del ave con su vuelo" (2006: 370). La búsqueda, por lo común, se tornará desesperada. La necesidad de alcanzar un orden diurno se volverá absoluta ante la angustia provocada por el hundimiento completo de lo sensible en lo increado; el dios se contemplará ahora como fiera, naturaleza animal donde no hay lugar para un rayo de luz: "Ahora se sumerge / bajo la luz la luz. / Esperar es aún / el lote nuestro. / Fino animal de sombra / que unifica la noche" (Valente, 2006: 371). En este punto el autor se adentrará en lo más caótico de la naturaleza, allá donde buscará en balde la raíz de la palabra, la raíz de todo su mundo sensible, no encontrando más que un cosmos en eterna transformación como manifestación de un orden desespiritualizado y puramente material: "OBJETOS de la noche. / Sombras. / Palabras / con el lomo animal mojado por la dura / transpiración del sueño / o de la muerte" (Valente, 2006: 377).

El encuentro con el deseado fondo matriarcal, identificado por el poeta como particularmente sensible y lejano a la abstracción, le situará en un pozo de oscuridad, de sombras donde no habrá espacio para el desenvolvimiento hacia lo cualitativo, hacia aquel poso espiritual propio de la imagen simbólica. La descripción que el poeta ofrece de este paisaje va a aludir una y otra vez a elementos devoradores, sombríos e incapaces de mostrar una esencia permanente, prontos a deshacerse, a disolverse, configurando un espacio terriblemente claustrofóbico en tanto que no se podrá conquistar la ansiada confluencia entre aquellos polos opuestos necesarios para la satisfactoria resolución de una poética desarrollada en los limos de lo larvario pero deseosa de alcanzar el ámbito de lo trascendental.

\section{EL SÍMBOLO, LA UNIDAD}

Será desde un estado de completo apagamiento donde el poeta comenzará a conquistar símbolos mediadores capaces de elevar el lenguaje hacia la luz sin por ello desvincularse de su fuente primera y elemental. Así, imágenes como la rama, el ala o el ángel comenzarán a hacer acto de aparición aunando cada 
una de ellas en su figura dos opuestos hasta entonces irreconciliables. La raíz quedará -en consecuencia- vinculada a la copa a través de la rama; la sierpe con el ave mediante la imagen del ala; y lo humano con lo divino mediante la aparición de un ángel que, comprendido como elemento mediador por excelencia, va a conseguir plasmar el feliz acuerdo en el poema homónimo extraído de Material memoria. El sujeto lírico, en estos versos, se dirigirá a la naturaleza angélica con las siguientes palabras: "No separes / la sombra de la luz que ella ha engendrado" (Valente, 2006: 379). El deseo de unidad va a resultar explícito en esta nueva plasmación del constante deseo de reunir la materia sensible con lo espiritual abstracto. Al respecto, cabe ofrecerse la significación concedida por Gilbert Durand, quien comprenderá a estos ángeles a modo de

símbolos de la función simbólica misma que es [...] mediadora entre la trascendencia del significado y el mundo manifiesto de los signos concretos, encarnados, que por medio de ella se transforman en símbolos (2007: 33).

Por ello, como mediadores de tendencia ascensional, símbolos logrados como este angélico posibilitarán con su presencia que todo comience a quedar preparado para escapar de unas aguas vivificadoras-disolutivas a las que el poeta, por tanto tiempo, se ha entregado.

La inmersión voluntaria en las aguas significa la aceptación de un momento de renuncia a la existencia, un instante de vacío, la conquista del vacío, la vuelta a los orígenes y la adquisición de una fuerza vital nueva (Valcárcel, 1989: 137);

El poeta habrá descendido a estas aguas con el propósito de recuperar su androginia esencial, con el fin de aprehender el aspecto puramente rítmico de su voz, la naturaleza generatriz de donde surge su palabra. Al respecto, el profesor Marius Schneider va a comentar que

se alcanza el punto culminante cuando una persona oye su melodía propia, es decir, la melodía de su propia alma, pero no cantada por ella misma, sino emitida por algo o alguien [...] a quien pertenece esa melodía. Nadie puede escapar al dictado imperioso de esta voz. Cuando un ser vivo se encuentra frente a aquel llamamiento de su propia alma exteriorizada, la atracción es fatal. Es la hora de la muerte (2001: 24). 
Esta muerte habrá que comprenderse como la desarticulación total de la personalidad, de la individualidad racional, lográndose mediante el vacío generado el libre surgimiento de lo poético hacia la superficie. Dicho ascenso llevará consigo la posibilidad de adquirir una densidad simbólica comprendida como identificación de unos órdenes con otros, es decir, como integración de diferentes estratos espirituales toda vez que lo individual cede a los requerimientos del conjunto, permitiéndose la correspondencia entre los diferentes elementos en tanto que el sentido de todos ellos es comprendido desde su necesaria completitud. En estos momentos, escasos y fugitivos en su desarrollo total dentro de la obra del gallego, no precederá el tronco a la rama o la sierpe al águila, pues las relaciones serán de esencia en lugar de causales. Las correspondencias dentro de un marco estético resultarán evidentes al no ser comprendida ya la materia como mero sustrato de la forma; de este modo, el universo sensible tratará de atestiguar su origen divino, dejando al artista, en cierto modo, al margen de su propia creación, manteniendo la actitud de mero catalizador entre unos y otros reinos y reduciendo lo absoluto al plano de lo estético. Este desarrollo será comentado por Ernst Cassirer al indicar que

la espiritualización de lo sensible trae como consecuencia inmediata la sensualización de lo espiritual en virtud del acto de sacrificio. Lo sensible es aniquilado en lo que se refiere a su existencia física y sólo en este aniquilamiento cumple con su función religiosa (2003: 282).

En el caso de nuestro poeta, del mismo modo, el símbolo habrá de ser sacrificado con el fin de alimentar las brasas de una creación nunca lo suficientemente completa en tanto que el vacío espiritual abierto no podrá ser colmado, siendo tanto el canto como el cantor nexos de unión logrados en el imaginario del poeta por sólo un instante para al siguiente quedar nuevamente enfrentados a un abismo presente en todo momento en tanto que situado al margen de su cosmos sensible. En consecuencia, el símbolo, pese a reunir dos distanciados órdenes poéticos, quedará ineficaz de cara a solucionar el conflicto existencial observado en el sentir espiritual del poeta en tanto que, como elemento deudor no sólo de lo espiritual, sino también de lo material sensible, no se logrará trascender el universo imaginario que paulatinamente, cada vez que se ha creído alcanzar un estrato liminar, se irá progresivamente ampliando. 


\section{BREVE APROXIMACIÓN FENOMENOLÓGICA A LOS ABISMOS}

$\mathrm{Al}$ margen de presupuestos puramente simbólicos, realizando un breve acercamiento fenomenológico al hecho estudiado, el descenso al reino de los arquetipos puede comprenderse desde el deseo de sustituir una aproximación al mundo meramente sensible, por una intelección ontológica, espiritual. El rechazo de todo lastre cognitivo conseguido mediante el descenso a las aguas primordiales donde todo residuo de conciencia se apaga en la noche común de lo que aún no ha nacido, invitará al poeta a acercarse a la realidad no ya a través de sus diferencias, de lo meramente formal, sino a través de sus convergencias íntimas. Se produce así el desplazamiento de una mirada externa por aquella otra espiritual que al proyectarse no va a chocar con la materia sino que la atravesará para de esta manera desplazarse, en último término, hacia aquella infinitud donde se espera la epifanía de lo sagrado. La visión del poeta, como la del pintor según la comprensión realizada por Maurice Merleau-Ponty, "no es ya mirada hacia fuera, relación 'física-óptica' solamente con el mundo. El mundo no está más frente a él como representación" (1964: 52), sino como cuerpo vivo que abre su interioridad, su naturaleza anímica, ante la luz emanada no ya del exterior sino desde el interior del creador, desde su poético acto de visión: "REPENTINA aparición de tu solo mirar" (Valente, 2006: 384). Esta visión dejará entonces de comprenderse como individual para pasar a ser lanzada desde aquel fondo ciego contemplado con terror al poco del descenso; recinto sagrado desde donde respira el ánima, tomando como referencia la terminología propia de Jung. En este sentido, según comenta Henri Corbin,

la visión imaginadora testimonial [...] se hace visión del corazón [...], es decir, visión del ojo interior [...], que es la visión de Dios por sí mismo, siendo el corazón el órgano, el 'ojo' por el que Dios se ve a sí mismo (1993: 269).

Cuanto se habrá logrado con este descenso no es sino una completa desindividuación, toda vez que no será ya el sujeto lírico quien arroje su mirada, sino "LA REPENTINA aparición de tu solo mirar" (Valente, 2006: 384), luz no poseída por el poeta sino surgida a través de él una vez que éste se retira como sujeto y permite que ascienda hacia él -de modo opuesto al acto de inspiración platónica-, el espíritu poético.

El poeta se retira surgiendo entonces la obra, de modo paralelo al he- 
cho mismo de la Creación tal y como es expuesto desde una cábala hebrea tan estudiada por Valente. El creador habrá entrevisto en su seno su fondo divino, coincidente con su materialidad, sin llegar, no obstante, a conocer el fundamento último de ésta, motivo de duda y temor en tanto que aún aspira a lograr el místico encuentro con la divinidad:
Mientras empañe el hálito
las palabras escritas en la noche
no moriré.
Mientras la sombra de aquel vientre baje
hacia el vértice oscuro del encuentro
no moriré (Valente, 2006: 386).

En este vientre, en este vacío, del mismo modo que en un orden simbólico hemos venido estudiando, albergará el sujeto su verbo a modo de primer acto del proceso de creación. El presente vacío -motivo dominante de una estética de marcado carácter minimalista tendente a manifestar no ya lo conformado, la representación, sino la nada sobre la que se asienta cuanto se va creando-será asociado por el autor con el espacio propio donde habrá de acontecer, de darse el caso, la divinidad.

Crear -nos indica el gallego en las páginas de 'Cinco fragmentos para Antoni Tàpies' - no es un acto de poder (poder y creación se niegan); es un acto de aceptación o reconocimiento. Crear lleva el signo de la feminidad. No es un acto de penetración en la materia, sino pasión de ser penetrado por ella (Valente, 2006: 387).

La posición del poeta ante el mundo no va a quedar determinada desde su actividad sino desde su pasividad, presentando su obra, presentándose a sí mismo, a modo de lienzo sobre el que se han de registrar cada una de las realidades que se desean expresar. La función del creador no será por tanto la de construir sino la de vaciar, la de retirarse del mundo fenoménico para que en el espacio generado haga su aparición lo sagrado comprendido como fuerza primaria cuyo último sentido quedará completamente desconocido. El "vacío puro", por consiguiente, será comprendido como "el estado supremo hacia el cual tiende todo artista" (Cheng, 1989: 77), definiéndose la búsqueda estética de Valente en estos estadios primeros de su creación desde la consecución de un espacio de desconfiguración del yo, pues, como el propio autor señalará, 
lo único que el artista acaso crea es el espacio de la creación. Y en el espacio de la creación no hay nada (para que algo pueda ser en él creado). La creación de la nada es el principio absoluto de toda creación (2006: 387).

\section{CONCLUSIÓN}

Como medio de negación de un mundo alumbrado exclusivamente por los hechos y no por el espíritu, como modo de rechazo de un sentido positivo de la historia, el descenso de José Ángel Valente a la materia queda enraizado a la salida de lo cronológico y a la entrada en lo atemporal. El poeta, con este adentrarse en sus estratos oníricos, buscará vaciarse de todo tipo de esquemas conceptuales, de un mundo de categorías poéticamente falsas en función de una superposición de filtros racionales sobre aquella voluntad pura tan querida en tanto enraizada en un orden materno. Esta huida del orden racional permitirá el advenimiento de todo un mundo sensible comprendido como naturaleza viva, como sustancia pura aún sin sedimentar $y$, en consecuencia, poéticamente verdadera. En función de este desarrollo, cada uno de los elementos simbólicos que van a ir apareciendo lograrán en su completo desarrollo una identificación entre lo comprendido como instintivo y lo comprendido como racional, en tanto que, desarticuladas todas las categorías lógicas, imágenes en principio aisladas van a converger como vasos comunicantes de una misma realidad. En último término, podemos comprender este intenso deseo de reunión entre diferentes estratos, como estético modo de resolver aquella polaridad más honda y esencial propia del universo poético de José Ángel Valente. Esta dualidad, recordamos, será comprendida por nuestro autor por medio de dos órdenes en principio opuestos, uno matriarcal y material, donde el poeta va a encontrar su natural lugar de ser, y aquel otro patriarcal y espiritual dominado por una serie de dogmas, de ortodoxias llamadas a sustituir un orden natural por otro artificial; este último orden será enteramente rechazado por el poeta pese a que tratará de adentrarse en él en tanto que se comprende este abismo como hipotético lugar de aparición de un Dios. En cualquier caso, dada la resistencia del poeta a despojarse de toda imagen, de toda lírica voz, no logrará adentrarse satisfactoriamente en este espacio de lo abismal.

Con el descenso a los estratos elementales de conciencia al que hemos asistido a lo largo de estas páginas, el poeta logrará la creación de un vacío necesario para el libre flujo de su voz. El resultado de estas indagaciones quedará plasmado, como hemos podido observar, mediante un hermoso cuadro 
pleno de sensibilidad, de imaginación material, del que el creador sólo saldrá ya para tratar de dar satisfacción a unos deseos metafísicos observables en un posterior y último momento de su trayectoria poética.

\section{REFERENCIAS}

Cassirer, Ernst. (2003). Filosofía de las formas simbólicas II. México: Fondo de Cultura Económica.

Certeau, Michel de. (2006). La fábula mistica. Madrid: Siruela.

Cheng, François. (1989). Vacío y plenitud. Caracas: Monte Ávila.

Cirlot, Juan Eduardo. (2005). En la llama: poesía (1943-1959). Madrid: Siruela.

Corbin, Henry. (1993) [1969]. La imaginación creadora en el sufismo de Ibn'Arabî. Barcelona: Destino.

Durand, Gilbert. (2007) [1964]. La imaginación simbólica. Madrid: Amorrortu.

Foucault, Michel. (2010) [1966]. Las palabras y las cosas. Madrid: Siglo XXI. García, Eduardo. (2010). José Ángel Valente: el refugio-matriz o la tentación del vacío. En Marta Agudo y Jordi Doce (eds.), Pájaros raíces. En torno a José Ángel Valente. Madrid: Abada.

Jung, Carl Gustav. (2002). Mysterium coniunctionis. Madrid: Trotta.

Merleau-Ponty, Maurice. (1964). L'Oeil et l'Esprit. Paris: Gallimard.

Neumann, Erich. (2009). La Gran Madre. Una fenomenología de las creaciones femeninas de lo inconsciente. Madrid: Trotta.

Otto, Rudolf. (2009). Lo santo. Madrid: Alianza.

Schneider, Marius. (2001). El origen musical de los animales-simbolos en la mitología y la escultura antiguas. Madrid: Siruela.

Valcárcel López, Eva. (1989). El fulgor o la palabra encarnada. Imágenes y simbolos en la poesía última de José Ángel Valente. Barcelona: PPU.

Valente, José Ángel. (1980). Punto cero: (poesía 1953-1979). Barcelona: Seix Barral.

. (2006). Obras completas 1. Poesía y prosa. Barcelona: Galaxia Gutenberg/ Círculo de Lectores.

Valente, José Ángel y Nuria Fernández Quesada (ed.). (2000). Anatomía de la palabra. Madrid: Pre-Textos. 
